\title{
The global oceanic freshwater cycle: A state-of-the-art quantification
}

\author{
by J. J. Schanze ${ }^{1}$, R. W. Schmitt ${ }^{2}$ and L. L. Yu ${ }^{2}$
}

\begin{abstract}
The current capabilities of quantifying the oceanic freshwater cycle are shown based on new observations from satellite data and re-analysis models for evaporation and precipitation over the ocean. For this purpose, we analyze the homogeneity and internal consistency of eight evaporation and seven precipitation products. Discontinuities are found around 1987 for all datasets, attributable to the launch of a microwave imaging satellite. Based on a review of comparisons with independent data and these analyses, the Global Precipitation Climatology Project (GPCP) and the Objectively Analyzed Ocean-Atmosphere Fluxes (OAFlux) evaporation product are combined with a state-of-the-art river discharge dataset to produce a new estimate of the global oceanic freshwater cycle for 1987-2006. The annual mean precipitation into the ocean averaged over 19 years is estimated at $12.2 \pm 1.2 \mathrm{~Sv}$, the evaporative loss at $13.0 \pm 1.3 \mathrm{~Sv}$, and the total freshwater input from land at $1.25 \pm 0.1 \mathrm{~Sv}$. The oceanic budget closes within the errors estimated for each data set with an imbalance of $0.5 \pm 1.8 \mathrm{~Sv}$. Based on this quantification, the global patterns of oceanic freshwater fluxes are described and a global mean is integrated to provide estimates of freshwater fluxes between basins. We find the Atlantic to be less evaporative and the Pacific less precipitative than previous in-situ estimates.
\end{abstract}

\section{Introduction}

The freshwater cycle is a crucial part of the Earth's climate system and provides one of the most important resources to support human life. Freshwater is transported between and stored in oceans, land, the atmosphere and the cryosphere. While the total amount of water on Earth has remained virtually constant over human timescales, the relative distribution of that total mass between the four reservoirs has been influenced by past climate states, such as glacial cycles. The terrestrial freshwater cycle has been investigated more extensively than its oceanic counterpart, largely due to a greater availability of data over land.

The oceans account for $71 \%$ of the Earth's surface area (Hartmann, 1994), and 86\% of evaporation (E) and $78 \%$ of precipitation (P) occur over the ocean (Baumgartner and Reichel, 1975; Adler et al., 2003). From the apparent imbalance of E-P over the ocean,

1. MIT/WHOI Joint Program in Oceanography, Woods Hole Oceanographic Institution, Woods Hole, Massachusetts, 02543, U.S.A. email: schanze@mit.edu

2. Department of Physical Oceanography, Woods Hole Oceanographic Institution, Woods Hole, Massachusetts, 02543, U.S.A. 
it is clear that the terrestrial and the oceanic components are closely interconnected. To gain an understanding of the complete hydrological cycle and its effects on global climate dynamics, it is thus imperative that the oceanic component be understood and quantified. To understand whether local changes might represent trends or natural variability, it is necessary to accurately quantify this cycle on timescales ranging from months to decades.

One of the most comprehensive studies of the world water balance, the results of which are still in wide-spread use today, was conducted by Baumgartner and Reichel (1975). Since this study, which was based solely on in-situ measurements, satellites have provided a nearsynoptic picture of some of the variables required to quantify the hydrological cycle. With more than 30 years of new data and a number of new datasets and estimates available (e.g. Quartly et al., 2007; Yu et al., 2008, and references therein), the following questions arise: Are we able to gain a clearer understanding of precipitation, evaporation and freshwater discharge into the ocean? Are we able to close the oceanic water budget between evaporation, precipitation and runoff? Is it possible to determine trends in the hydrological cycle with the present data? To answer these questions, a careful analysis of presently available datasets along with their temporal and spatial homogeneity is required.

In Section 2, we describe how $\mathrm{E}$ and $\mathrm{P}$ observations have benefited from technological advances in the last 30 years, including remote sensing technology and modern computer systems. In Section 3, we describe seven E and seven P datasets and review recent intercomparisons. We analyze each dataset for inhomogeneities and produce a table of the mean global balance between each of the datasets in Section 4. In Section 5, based on a review of inter-comparisons, we present a combination of the Global Precipitation Climatology Project (GPCP) and the Objectively Analyzed Ocean-Atmosphere Fluxes (OAFlux) product as well as riverine runoff (Dai and Trenberth, 2002; Dai et al., 2009) and compare it to other recent estimates.

\section{a. The sampling problem}

The basic components of the hydrological cycle are precipitation, evaporation, transpiration, riverine runoff, groundwater seeps, and ice fluxes. Precipitation occurs globally over the land, the ocean and the cryosphere, and is defined as any product of condensation, with the most common forms being rain and snow. Evaporation occurs globally also, but is significantly reduced in the cryosphere, where sublimation of ice is the dominant mechanism. On land, evaporation from soil and transpiration from plants may be combined to give evapotranspiration. Riverine discharge $(\mathrm{R})$ into the ocean is the second most important freshwater input after oceanic precipitation. Groundwater seeps are sometimes included in the total R, but inputs from the cryosphere, such as the breaking away of icebergs from permanent ice-shelves on and around Greenland and Antarctica are usually accounted for separately (Dai et al., 2009, and references therein).

Measurements of precipitation and evaporation over land have been collected for multiple centuries (e.g. New et al., 2001; Roderick and Farquhar, 2002, respectively). Early 
measurements consisted of rainfall gauges which were little more than buckets to measure precipitation. Evaporation was traditionally measured by gauging the decrease in fluid level in water-filled pans. Over time, these systems were improved to account for shortcomings, such as the loss of water due to splashing caused by the momentum of heavy raindrops. A classification system of the required accuracy was introduced to standardize measurements of evaporation and precipitation over land (Brutsaert, 1982), but for social and political reasons, observations were, and still are, inhomogeneous in both space and time. A high data density is available for most of Europe, the United States, Australia and some parts of Asia (particularly India), while large parts of Africa, continental South America, some regions of Asia and northern North America remain comparatively sparsely sampled (New et al., 2001). Additionally, the availability of in-situ data can be delayed by several years to multiple decades due to political conflicts or a lack of reciprocal data exchange between agencies.

\section{b. Defining oceanic freshwater fluxes}

Riverine inflow accounts for approximately $10 \%$ of the total freshwater input to the ocean (Dai and Trenberth, 2002). The spatial distribution of these inputs can be difficult to deal with, since some large rivers - such as the Amazon - form large deltas which span hundreds of kilometers of coastline and have multiple inflows into the ocean. One can thus attempt to define every point of inflow to the ocean, or specify the total outflow of all parts of the delta at the dominant outflow point. Since this research is focused on basin-scale and global balances, the dominant outflow point is used as specified in Dai and Trenberth (2002) and Dai et al. (2009). While this approach is appropriate for the purpose of producing a global balance, it is important to consider the effects of riverine discharge plumes and the resulting mixing with the surrounding saltwater when studying regional effects or local buoyancy forcing.

Another source of freshwater to the ocean originates from the cryosphere. It is a common misconception that melting sea-ice constitutes an addition of freshwater to the ocean. Any ice which floats in the ocean displaces the same volume of water in its frozen state as if it were completely melted. This is not true for grounded ice, the weight of which is supported by land. The calving of a previously grounded ice sheet into the ocean as an iceberg thus constitutes a net freshwater influx (Shepherd and Wingham, 2007). Therefore, precipitation over sea-ice can be treated as precipitation over open water for purposes of creating a long-term freshwater budget. Clearly, the presence of sea-ice needs to be considered more carefully for short-term fluctuations, as freshwater might be stored in sea-ice and icebergs rather than mixing with the surrounding water.

Not all freshwater fluxes in the ocean occur in the form of freshwater. While all E, P and $\mathrm{R}$ can be taken to have zero salinity, the exchange of freshwater between ocean basins occurs within volume transports that are generally on the order of 10-100 times larger than the freshwater transports associated therewith. One can thus discuss the flux of freshwater 
by separating seawater into liquid ('freshwater') and solids remaining during complete evaporation ('salt') by weight, as was done by Wijffels et al. (1992). Alternatively one may define freshwater anomaly flux relative to a reference salinity.

\section{New sources of data}

There are two main methods to produce a global $\mathrm{E}$ or $\mathrm{P}$ dataset: the use of computational models, most commonly (re-)analyses (RA) and the use of statistical methods, such as objective analysis (OA). Both methods are heavily dependent on the input data to which they are constrained (see e.g. Wunsch and Heimbach, 2007). In this section, we discuss basic properties as well as merits and problems of both types of datasets.

While the availability of land-based measurements is limited both spatially and temporally, it is abundant in contrast with even sparser historical observations over the ocean. Before the advent of oceanographic satellites, ship-borne in-situ measurements were needed to gather any data. Large areas which were not frequented by vessels, such as the Southern Ocean, remained virtually unsampled. This situation would only change with the availability of various satellite sensors that allow the determination of four primary oceanic variables: sea-surface temperature (SST), sea-surface roughness, which to lowest order is a function of wind speed, $U_{\text {air }}$, ocean color and sea-surface height (Robinson, 2004). Additionally, it is possible to gain insight into various atmospheric parameters, such as moisture content, primarily through satellite-borne active radar instruments. From these variables it is possible to derive - by the use of empirical formulas and data assimilation models - evaporation fields as well as rainfall over the ocean on a near-global scale with good temporal and spatial resolution.

The advances in computer technology in the last few decades have facilitated the use of computational fluid dynamics and numerical weather prediction for large data assimilation models such as those of the National Center for Environmental Prediction/National Center for Atmospheric Research (NCEP/NCAR) and the European Centre for MediumRange Weather Forecasts (ECMWF). These RA models enable the computation of the time-evolution of a given state and seek to minimize the error between a computed state and given observations at a later time. As a consequence, it is possible to 'fill in' the gaps in regions with low data density based on our physical understanding of the system and parameterizations of governing processes which are too complex to model directly. The input data used to constrain such models are not limited to in-situ data, but generally include remotely sensed satellite data such as SST, $U_{\text {air }}$ and remotely sensed atmospheric data. The outputs of such models are in widespread use today. Such models include the NCEP/NCAR Global Reanalysis Project 1 (Kistler et al., 2001), hereafter NCEP-1, available from 1948-present, the NCEP/NCAR Global Reanalysis Project 2 (Kanamitsu et al., 2002), hereafter NCEP-2, which is constrained to satellite data for the entirety of the analysis period (1979-present), the Modern Era Retrospective-Analysis for Research and Applications (Bosilovich et al., 2006), hereafter MERRA (1979-present), the ECMWF Re-Analysis 40 (Uppala et al., 
Table 1. Global annual $(\mathrm{P}+\mathrm{R})$-E balances between precipitation datasets (rows) and evaporation datasets (columns) in $\mathrm{Sv}\left(10^{6} \mathrm{~m}^{3} \mathrm{~s}^{-1}\right)$ for major objectively analyzed and re-analyzed datasets. Positive imbalances indicate an apparent excess input of freshwater to the ocean, while negative values indicate net water loss. Flux data are averaged between 1987-2006 or the longest common available period within 1987-2006. The combined river discharge $(\approx 1.25 \mathrm{~Sv})$ from Dai and Trenberth (2002) and Dai et al. (2009) has been added to all precipitation products. Such balances are sensitive to the land-mask used, so a common land-mask was used for these estimates.

\begin{tabular}{|l||c|c|c|c|c|c|c|}
\hline P+R & OAFlux & NCEP-1 & NCEP-2 & ERA-40 & ERA-Int & CORE.2 & MERRA \\
\hline \hline GPCP & +0.46 & -0.41 & -2.24 & -1.00 & -1.15 & -0.69 & +0.22 \\
\hline NCEP-1 & +1.05 & +0.18 & -1.65 & -0.45 & -0.54 & -0.11 & +0.81 \\
\hline NCEP-2 & +3.28 & +2.42 & +0.59 & +1.65 & +1.70 & +2.13 & +3.05 \\
\hline ERA-40 & +3.87 & +3.04 & +1.30 & +2.41 & +2.70 & +2.70 & +3.61 \\
\hline CMAP & +0.90 & +0.03 & -1.80 & -0.53 & -0.71 & -0.26 & +0.66 \\
\hline CORE.2 & +1.01 & +0.15 & -1.69 & -0.45 & -0.60 & -0.14 & +0.78 \\
\hline MERRA & +0.47 & -0.40 & -2.23 & -1.30 & -1.14 & -0.69 & +0.23 \\
\hline
\end{tabular}

2005), hereafter ERA-40, which is available 1957-2002, as well as follow-on projects of the ECMWF, such as the ERA-Interim dataset (Simmons et al., 2007).

The other method to produce a regularly spaced global dataset is objective analysis, which is a statistical model for gridding irregularly spaced data based on de-correlation time- and space-scales. It is also used to combine regularly gridded datasets with different error estimates. Using weightings based on the error estimates provided by each dataset, it is possible to produce an objectively analyzed product (e.g. Yu and Weller, 2007; Yu et al., 2008, and references therein). The OA of data is based on a statistical rather than a physical model. Consequently, unlike a re-analysis, its purpose is not to predict the time-evolution of the system, but to find the optimal solution of an objective function. Since the objective function is weighted proportionally to the error covariance of the input data, more weight is given to data with lower error estimates (Yu et al., 2008). The homogeneity of objectively analyzed datasets is thus highly dependent on the quality and quantity of the input data.

We will examine the properties of both types of datasets in the next sections by analyzing the homogeneity and closure of two OA based E datasets, five RA based E datasets, three OA based $\mathrm{P}$ datasets and four RA based $\mathrm{P}$ datasets (see Table 1). Brief literature reviews of inter-comparisons of $\mathrm{E}$ and $\mathrm{P}$ datasets are used to assess the overall suitability of the datasets to produce a global multidecadal estimate of the oceanic freshwater cycle.

\section{a. New evaporation data}

For a robust estimate of evaporation using the bulk flux formula (Fairall et al., 2003), the SST, the surface wind speed at $10 \mathrm{~m}$, the specific humidity and the temperature of the air overlying the sea surface at $2 \mathrm{~m}$ must be known. Of these four variables, two are observable from satellites. SST can be inferred from measuring the infrared- and microwave-emissivity 
Table 2. Dates of first continuous availability of data sources. In-situ measurements prior to 1948 are not considered. Only commonly used satellite missions which enhanced the data quality significantly are listed. New sources are only listed if they provide a potential significant advantage in the future. $\dagger$ - These data sources are not commonly used in order to preserve data homogeneity. $\$-$ Even though AVHRR was first launched in 1978 and was fully operational from 1981 onwards, sufficient buoy data to constrain the data are only available after 1985.

\begin{tabular}{l|l|l|l}
\hline Data & \multicolumn{2}{c}{ Variable } & Available \\
\hline \multirow{4}{*}{ E } & all & in-situ and NWP & 1948 \\
\cline { 2 - 4 } & $T_{\text {sea }}$ & AVHRR & $1985 \ddagger$ \\
& & AMSR-E $\dagger$ & 2002 \\
\cline { 2 - 4 } & $U_{\text {air }}$ & SSM/I & 1987 \\
& & QuikSCAT & 1999 \\
\cline { 2 - 4 } & $T_{\text {air }}$ & in-situ/NWP only & 1948 \\
\hline & $q_{\text {air }}$ & SSM/I & 1987 \\
& & AIRS $\dagger$ & 1999 \\
\hline & Ptotal & in-situ and NWP & 1948 \\
& & OPI & 1979 \\
& & GPI & 1986 \\
& & SSM/I & 1987 \\
& & TOVS & 1987 \\
& & TRMM-TMI $\dagger$ & 1997 \\
\hline
\end{tabular}

of the sea surface, while wind speed can be determined from scattering, attenuation or variability of an active radar signal from a satellite (e.g. Robinson, 2004, and references therein). It is also possible to determine the atmospheric moisture content and hence surface humidity with active radar sensors (Schulz et al., 1993; Chou et al., 1995, 2003), though such estimates are not in widespread use. While observations of atmospheric temperatures are in principle possible from satellite platforms, measurements sufficiently near the sea surface $(\approx 2 \mathrm{~m})$ are not possible or are indistinguishable from SST (Divakarla et al., 2006). Consequently, this quantity is commonly derived from in-situ measurements or from reanalysis models (Yu et al., 2008).

To understand historical data limitations, one must consider the temporal evolution of data availability. This time-line is summarized in Table 2. While high-resolution SST data became available as early as 1978, and continuously available from 1982 onwards, the accuracy of observations from the Advanced Very High Resolution Radiometer (AVHRR) was significantly improved with a match-up database to buoy measurements which started in 1985 (Smith et al., 1996). The Defense Meteorological Satellite Program's (DMSP) first Special Sensor Microwave Imager (SSM/I) instrument was operational in July 1987 and has been continued by follow-on missions (e.g. Robinson, 2004, and references therein). This sensor has brought about several enhancements for variables used in both evaporation and precipitation datasets. For evaporation, SSM/I was the first satellite to provide estimates of sea-surface roughness, and consequently a global picture of wind speeds (Goodberlet $e t$ al., 1990) as well as specific surface humidity from column water vapor estimates (Chou et al., 2003). 


\section{b. New precipitation data}

Due to its ability to determine water vapor content, the SSM/I mission made it possible to estimate precipitation based on attenuation of high-frequency radar due to volume scattering of precipitation, particularly those of freezing ice crystals at high altitudes. Information on the vertical humidity structure of the air can be inferred by the differential attenuation of four radar bands ranging from 19.35-85.5 GHz (Spencer et al., 1989). The lower frequencies are dominated by precipitation above the freezing level, and from this the type of precipitation can be estimated (Spencer et al., 1989). Since rainfall is transient and localized, it is necessary to maximize the temporal sampling. While the re-visit interval of approximately 1 day is temporally inferior to a long term in-situ precipitation measuring station, the spatial coverage, particularly over the ocean, is vastly superior.

Since a strong correlation exists between the height and temperature of the top of tropical clouds and precipitation, it is possible to use infrared measurements from geostationary satellites to provide the necessary temporal coverage for precipitation estimates (e.g. Adler et al., 2003, and references therein). However, such observations are spatially limited to the area over which the satellite is positioned, and the empirical relationship between cloudheight and cloud-top temperature and the resulting precipitation is influenced by other parameters, with estimation uncertainties increasing toward higher latitudes. For this reason, precipitation estimates are superior in tropical and subtropical regions compared to poor spatial and temporal coverage in polar and subpolar regions.

More recent satellite data sources, such as the Tropical Rainfall Measuring Mission (TRMM) are able to provide even better estimates of precipitation due to dedicated on-board precipitation radar instruments. TRMM data have only been available since November 1997, and as a result, the length of the record is short compared to other satellite observations. The spatial sampling is also concentrated on tropical and subtropical latitudes due to the satellite's orbital inclination of $35^{\circ}$, restricting even swath observations to a maximum latitude of $\pm 40^{\circ}$.

\section{c. Re-analysis models}

In data re-analysis, a data assimilation model is utilized for processing past observations to generate a constrained short-term forecast and to find state-estimates at given time-steps. It is the aim of a re-analysis model to simulate physical processes, and as such the models are based on governing physical equations (such as the primitive equations for the ocean and the atmosphere) as well as parameterizations for important physical processes. In the case of NCEP-1, these parameterizations include: "convection, large-scale precipitation, shallow convection, gravity wave drag, radiation with diurnal cycle and interaction with clouds, boundary layer physics, an interactive surface hydrology and vertical and horizontal diffusion processes" (Kistler et al., 2001). The NCEP-1 assimilation system utilizes a global spectral atmospheric model with 28 vertical levels and an equivalent horizontal resolution of $209 \mathrm{~km}$. While other models use different geometries, parameterizations and 
sources of constraining data, the concept of re-analysis of data is the same amongst all such products.

Since the underlying model does not change over time, one might expect that the output of such models is virtually homogeneous, even if the data are insufficient to constrain the model to great accuracy. However, climatological discontinuities due to the introduction of satellite data have been identified in the NCEP-1 reanalysis (Sturaro, 2003) as well as in ERA-40 (Sterl, 2004). Sturaro (2003) concludes that this is due to the changing density of data to constrain the assimilation model, based on comparisons with observations and a simple bulk flux algorithm for evaporation utilizing sea-surface temperature (SST) records. The homogeneity of a re-analysis model is thus not guaranteed but, akin to an OA model, strongly dependent on the homogeneity of the input data.

\section{Global evaporation and precipitation data sets}

In this section, we describe seven global $\mathrm{E}$ and seven global $\mathrm{P}$ datasets that are in common use today and review some inter-comparison to assess their quality. We also discuss current estimates of $\mathrm{R}$ and ice-fluxes into the ocean.

The assessment of the quality of both $\mathrm{E}$ and $\mathrm{P}$ global datasets is difficult, as it strongly depends on the desired application, since products have different strengths and weaknesses in different areas (Quartly et al., 2007). If trends are to be identified, the homogeneity as well as the temporal and spatial coverage of the product are important factors. A stateof-the art data assimilation system is required to maximize the amount of temporal and spatial information available (Yu and Weller, 2007; Adler et al., 2003). For robust estimates of $\mathrm{E}, \mathrm{P}$ and their variabilities, a dataset needs to be able to span periodic events such as the El Niño Southern Oscillation (ENSO), which produces significant changes to both E and P patterns (Curtis, 2008). Consequently, such a time-series should span significantly longer than a decade. It should be noted that natural variability occurs on all time- and space-scales, and it is not implied that trends longer than such inter-decadal events are not attributable to natural variability. This further complicates the identification of trends in such datasets.

To preserve data homogeneity, a trade-off between the incorporated and the available data must be made - in the case of the Global Precipitation Climatology Project (GPCP) (Adler et al., 2003), this trade-off results in the exclusion of TRMM data in the most recent (version 2.1) dataset due to the relatively short availability and the inhomogeneities that would otherwise occur. For this reason, TRMM data are not used in any long-term merged $P$ dataset known to the authors at the time of writing. Similar concessions must be made for E datasets, in which microwave observations from sensors such as the Advanced Microwave Scanning Radiometer-E (AMSR-E) are not included due to their ability to sense SST below cloud cover. While SST data under clouds may be able to improve estimates of E, the inclusion would introduce a discontinuity by changing the systematic bias that is generated by sensing SST by infrared satellites only (Yu et al., 2008). 
Since not all data are ingested into the respective datasets, it is possible to use such independent data for validation purposes. Buoy in-situ observations for evaporation and TRMM observations for precipitation have been used in inter-comparisons of E (Josey, 2001; Yu et al., 2008) and P (Yin et al., 2004; Quartly et al., 2007). However, if a product uses all available data or is corrected to agree with in-situ or other independent data, an intercomparison may not be possible. Such is the case with the corrected version of the Common Ocean-ice Reference Experiments 2 (CORE.2) dataset (Large and Yeager, 2009). Some datasets span periods of more than 40 years, and as a result are expected to have temporal inhomogeneities due to changes in sensors during this time. To determine if inhomogeneities can be identified in such datasets, a homogeneity analysis is performed in Section 4 on all datasets discussed here to identify significant changes in data composition.

\section{a. Evaporation data sets and inter-comparisons}

The Objectively Analyzed Air-Sea Heat Flux (OAFlux) dataset (Yu and Weller, 2007; Yu et al., 2008) is constructed from an objective synthesis of remotely sensed satellite data and atmospheric re-analysis fields from the ERA-40, NCEP-1 and NCEP-2 re-analysis models to generate a state-of-the-art estimate of climatological fields relevant to air-sea fluxes. The methodology governing the objective analysis is the Gauss-Markov theorem (Yu et al., 2008). The Gauss-Markov theorem states that when data are combined in a linear fashion, the linear least squares estimator is the most efficient estimator. The error in each input data source is thus reduced to produce an estimate that has the minimum variance. While re-analysis estimates are used for quantities which are not directly observable from other sensors, OAFlux is not a re-analysis in itself. Fields that use satellite data include SST and surface wind speed at $10 \mathrm{~m}$ above the sea surface as well as wave height and cloud cover. Surface air temperature and relative humidity relative to $2 \mathrm{~m}$ above the surface are based solely on re-analysis products. Based on these fields, it is possible to estimate evaporation rates over the ocean using the Coupled Ocean-Atmosphere Response Experiment (COARE) Bulk Algorithm (Fairall et al., 1996, 2003).

The CORE. 2 dataset provides fields of air-sea fluxes, which, like OAFlux, are derived from bulk formulas. Atmospheric fields from multiple sources and an optimally interpolated merged SST product are input to the bulk flux formula to produce outputs at monthly resolution between 1948-2006. The atmospheric inputs are based on the NCEP re-analyses, while radiation data, $\mathrm{P}$ and sea-ice concentration are satellite-derived (Large and Yeager, 2009). The CORE. 2 product is available from NCAR (2010) and uses corrections to agree with satellite and in-situ measurements that are too short in duration or too regional in coverage to be used to constrain fields directly. While an uncorrected version also exists, this does not include E fields. We thus restrict our discussion of CORE.2 to the corrected fields.

A further OA E dataset is the National Oceanography Centre - Southampton OceanAtmosphere Heat, Momentum and Freshwater Flux Atlas (NOCS) (Josey et al., 1998) 
which is based on the Comprehensive Ocean-Atmosphere Data Set (COADS) (Woodruff et al., 1987) with additional in-situ observations. Since COADS does not include any satellite derived data, this dataset is affected by strong spatial biases due to the preferential sampling of areas often frequented by vessels (such as the North Atlantic), but since no transition between in-situ to satellite sampling is present, the homogeneity is good. Due to the issues of spatial biasing and insufficient global coverage, we do not consider in-situ-only datasets in our comparisons.

The most commonly used re-analysis products are the NCEP-1 (Kistler et al., 2001), NCEP-2 (Kanamitsu et al., 2002) and ERA-40 (Uppala et al., 2005) re-analyses, as well as several follow-on products, such as MERRA (Bosilovich et al., 2006) and ERAInterim. Some strengths and weaknesses of these estimations have already been discussed in Section 2c. All of the aforementioned reanalyses include evaporation and precipitation fields. While NCEP-1 spans a time period from 1947-2001, NCEP-2 was designed to be more spatially and temporally homogeneous (Kanamitsu et al., 2002) and consequently only starts with the availability of SST data in 1979, and ERA-Interim only begins in 1989 (Simmons et al., 2007). The ERA-40 re-analysis spans the time 1957-2001 (Uppala et al., 2005) and is thus affected by a change of input data from solely ship- and buoy-based observations to the inclusion of satellite data in the 1970s and 1980s. It should be noted that it is not the primary purpose of any re-analysis to estimate $\mathrm{E}, \mathrm{P}$ or a freshwater budget, but rather to produce estimates of a number of fields (Wunsch and Heimbach, 2007).

A number of buoys, such as the Prediction and Research Moored Array in the Atlantic (PIRATA) and the Tropical Atmosphere Ocean (TAO) project can be used to estimate errors in latent heat fluxes provided by all evaporation products and can thus be used to find the data product which most closely resembles the in-situ data. In a direct comparison of independent buoy-derived fluxes with NCEP-1 and ECMWF re-analysis fields and the NOCS flux fields (Josey, 2001), the mean errors between in-situ, NCEP-1, ECMWF and the NOCS fluxes, the lowest mean error was found for the NOCS dataset. However, it should be noted that all five buoys used in this comparison were located in the Northeast Atlantic, an area with a high coverage of ship-borne observations, and that the time-scale of observations extended for only two years from 1991-1993.

A similar comparison between in-situ measurements and $\mathrm{E}$ datasets was conducted by $\mathrm{Yu}$ et al. (2008) using a total of 107 observations of various lengths. All measurements were taken between 1988-2006, meaning that satellite data were available for the duration of comparisons. The OAFlux dataset exhibits the lowest errors in all flux estimates compared to NCEP-1, NCEP-2 and ERA-40. While the observations span the Indian, Atlantic and Pacific oceans, the locations of the observations are predominantly in equatorial and subtropical regions, with only four observations outside the $\pm 40^{\circ}$ latitude band. It thus appears that the OA datasets (NOCS, OAFlux) have the best agreement with independent measurements.

In an inter-comparison of different satellite-based and RA latent heat products in the South China Sea by Zeng et al. (2009), the TRMM Microwave Imager (TMI) and OAFlux datasets were found to be more closely correlated to in-situ data and to exhibit less systematic error 
than the ERA-Interim, and NCEP-2 re-analyses and the COADS estimate. The TMI data are not considered here, since the duration of available data (1997-current) is too short.

\section{b. Precipitation data sets and inter-comparisons}

A multitude of different precipitation datasets and climatologies are available today, offering different temporal and spatial coverage. In recent years, high-resolution satellite precipitation estimates with resolutions that are finer than or equal to $0.25^{\circ}$ and have temporal resolutions on the order of 3 hours have become available (see Sapiano and Arkin (2009) for an overview of such datasets). The data input of these estimates is based on a variety of satellite sensors, and does not produce a global coverage due to the high temporal and spatial resolution. Since many of the sensors used for input data were only launched in 2002 and subsequent years, the usable duration of such estimates is insufficient for the purposes of estimating a multidecadal picture of the oceanic freshwater cycle. Only products spanning significantly more than one decade will be considered.

As with evaporation datasets, both re-analyses and objective analyses exist. All reanalyses that were considered for E also provide fields for P; these include NCEP-1, NCEP-2, ERA-40 and MERRA. Also considered were the objectively analyzed merged gauge and satellite-derived CORE.2, CPC Merged Analysis of Precipitation (CMAP, see Xie and Arkin (1997) for details) and the Global Precipitation Climatology Project (GPCP) products. A re-analysis should be self-consistent and the layman might thus expect the E-P-R budget to close. However, since the underlying prediction models are generally forward-integrating (and thus have no information of the future), closure is not guaranteed (Wunsch and Heimbach, 2007) and is in fact violated for the freshwater cycle in all examined re-analyses. When the global balance of all investigated datasets is computed (Table 1), ERA-40 was found to add a net flux of approximately $2.41 \mathrm{~Sv}\left(1 \mathrm{~Sv}=10^{6} \mathrm{~m}^{3} \mathrm{~s}^{-1}\right)$ to the ocean. Given that the global $\mathrm{E}$ is $\approx 13 \mathrm{~Sv}$, this imbalance is approximately $20 \%$ of global $\mathrm{E}$ and clearly not physically possible, since it would imply a global sea-level rise of $0.21 \mathrm{~m} \mathrm{yr}^{-1}$. Based on this alone, the ERA-40 dataset can be rejected for analysis of the global oceanic freshwater cycle.

It has been shown in comparisons with independent measurements (Quartly et al., 2007) that GPCP showed a significantly higher correlation to the in-situ observations than fields provided by NCEP-1, NCEP-2 and ERA-40. Quartly et al. (2007) conclude that GPCP, although by no means perfect, represents the current best-estimate, even though increasing errors at high latitudes are a known problem of this product. This is caused by using an empirical correlation between cloud-top temperatures and precipitation, which is a good approximation in low latitudes, but degrades toward the poles (Adler et al., 2003; Yin et al., 2004). Comparisons of CMAP and GPCP found an overreliance on atoll and island data by CMAP (Yin et al., 2004), leading to unreasonable spatial distributions of $\mathrm{P}$ over the ocean. At the moment GPCP can be regarded as the state-of-the art long-timescale P product for use over the global ocean and will thus be used for purposes of this research. 
All data analysis was performed with the GPCP version 2.0 dataset. GPCP released an updated version 2.1 in July 2009. Changes to the Global Precipitation Climatology Center (GPCC) gauge analysis have increased net $\mathrm{P}$ estimates from gauges, resulting in higher estimates over the ocean in the pre-SSM/I era and higher land-based values overall. Since only the oceanic component of GPCP in the SSM/I era is considered here, no significant changes are expected between version 2.0 and 2.1 for the present estimate.

\section{c. Other sources of freshwater to the ocean}

One of the first comprehensive datasets of river gauge data and the resulting runoff from those fields was completed by Baumgartner and Reichel (1975). Measuring the outflow of a river into the ocean is a nontrivial problem, since it is often impossible to gauge the flow at the river-mouth. This is particularly true in river deltas, in which hundreds of outflows might be present, and it would be impractical to gauge every one. Therefore, gauging stations farther inland (sometimes up to hundreds or even thousands of kilometers) are used to estimate river flows. It is also possible to use the catchment area (the total land area that drains precipitation to a given river) for each river system and utilize $\mathrm{P}, \mathrm{E}$ and evapotranspiration products to estimate the total riverine discharge based on the conservation of water. However, this approach leads to the quality of the precipitation data determining the quality of the discharge data (Fekete et al., 2004). It is thus preferable to use gauging stations wherever and whenever possible. Such an approach has been taken by Dai and Trenberth (2002) in an updated global quantification of the world's rivers. This work was updated in 2009 (Dai et al., 2009) and includes previously unavailable data from gauging stations around the world.

While Dai and Trenberth (2002) provided discharges as averages for each month of the year with no information on inter-annual changes (i.e. all available data years in which the month January was available were merged to give a 'typical' January), inter-annual variability in riverine discharge was included by Dai et al. (2009). The standard deviation of the inter-annual variability, however, is found to be only $11 \%$ of that of the annual variability, indicating that the annual cycle has greater variability (Trenberth et al., 2007). The annual variability is predominantly caused by the accumulation and melting of snow and ice in the Northern Hemisphere, which contains significantly more land area than the Southern Hemisphere, particularly at temperate latitudes.

We have thus combined the mean seasonal information found in Dai and Trenberth (2002) with the inter-annual variability in Dai et al. (2009) to produce a monthly estimate of R which was used for all subsequent analyses. This combined estimate has an arithmetic mean of $1.18 \mathrm{~Sv}$, which is identical to the arithmetic mean of only the seasonal data from Dai and Trenberth (2002).

The Antarctic iceberg flux was estimated at $2288 \mathrm{~km}^{3} \mathrm{yr}^{-1}$, equivalent to $0.073 \mathrm{~Sv}$ by Vaughan et al. (1999). In a literature review, Monaghan et al. (2006) compare studies that use precipitation data and the total mass balance and find Antarctic ice-exports ranging from 1475 to $2331 \mathrm{~km}^{3} \mathrm{yr}^{-1}$ or 0.047 to $0.074 \mathrm{~Sv}$. The relatively large range of estimates is 
caused by the uncertainties in the precipitation measurements and the surface mass balance over Antarctica (Shepherd and Wingham, 2007).

Similar mass balance calculations have been performed for Greenland by Box et al. (2006) who found a total average meltwater/iceberg runoff of $373 \mathrm{~km}^{3} \mathrm{yr}^{-1}$ or $0.012 \mathrm{~Sv}$. To simplify the freshwater budget to E-P-R, the iceberg/meltwater discharges from both Antarctica and Greenland were included in the total riverine runoff to augment the mean annual riverine discharge of $1.18 \mathrm{~Sv}$ (Dai and Trenberth, 2002) by the mean of the available iceberg/meltwater observations for Antarctica and Greenland (0.06 and 0.01 Sv, respectively) to a total value of $1.25 \mathrm{~Sv}$.

Between 1993 and 2006, a sea-level rise of approximately $2.4 \pm 1 \mathrm{~mm} \mathrm{yr}^{-1}$, which would be equivalent to a net influx of $0.03 \mathrm{~Sv}$, was observed from satellite altimetry (Domingues et al., 2008). However, thermal expansion accounts for approximately $1 \mathrm{~mm} \mathrm{yr}^{-1}$ of this, rendering this change to below $0.02 \mathrm{~Sv}$. In comparison with the error estimates of $\mathrm{E}, \mathrm{P}$ and $\mathrm{R}$, which sum to approximately $1.8 \mathrm{~Sv}$, this is insignificant.

\section{Evaluation of homogeneity of evaporation and precipitation data}

The homogeneity of the data has to be considered carefully for the purposes of this study. By visual inspection of a time-series alone it becomes apparent that more spatial and temporal resolution is present in the data after 1987. To quantify these changes, an empirical orthogonal function (EOF) analysis was performed. The transitions can be illustrated by identifying changes in the time series associated with the loading patterns (see Figs. 1 and 2). The absolute value of the normalized amplitude of the associated time series is color-coded and all series are plotted above each other, beginning at the top with the leading mode (the mode explaining the most variability and containing the highest energy). The normalization ensures that all associated time-series have identical variances. While this allows the changes to be readily compared on the same scale, it should not be forgotten that lower-numbered modes are the most energetic and explain more variability than higher-numbered ones.

If a change in high-resolution information (be it increased spatial or temporal detail) is present, the intermediate modes (those explaining less variability, but not those at the level of noise) are expected to increase. When the interpolation problem is more constrained by data, the amplitude of the highest modes, equivalent to noise in the data, is expected to decrease. This is seen in modes greater than 270 for OAFlux evaporation (of a total of 348 modes, see Fig. 1) and modes greater than 400 in the case of GPCP precipitation (out of 588 modes, see Fig. 2). The sum of the explained variability of modes $270-348$ is $1 \%$ for GPCP and $0.6 \%$ for modes $400-588$ in the case of OAFlux.

Since this analysis is performed on monthly datasets, the output is smoothed using a two-dimensional Gaussian filter with half power points of 12 and 40, corresponding to 12 months in time [x-direction] and 40 modes [y-direction]. This filter is necessary to visualize inter-annual variability that would otherwise not be visible due to seasonal fluctuations in the associated time series. For OAFlux E, this analysis is shown in Figure 1. A first transition 


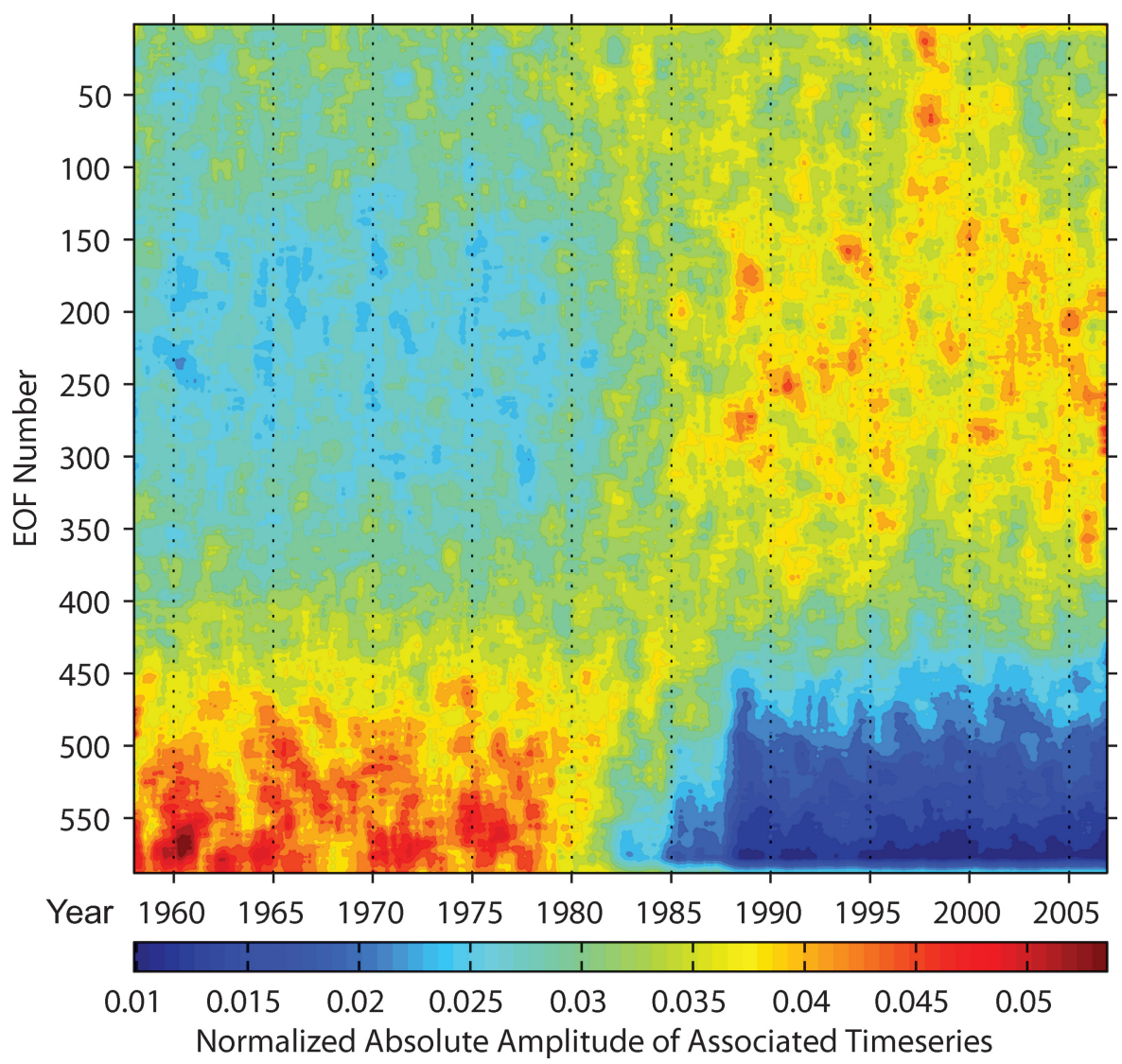

Figure 1. Filtered results of empirical orthogonal function (EOF) analysis of the OAFlux evaporation dataset. The magnitude of all associated time series (color-coded) is plotted with respect to time and the number of the EOF. Changes in the EOF modes 50-550 clearly indicate a strong change in data composition around 1982 and 1987, coinciding with the availability of sea-surface temperature data in 1982 and 1985 as well as SSM/I data in 1987. Natural variability associated with El Niño is evident around 1997-1998.

is evident in 1982 and after 1985 and a further change occurs in 1987, corresponding to the years in which verified SST from the AVHRR mission and wind speed from SSM/I became available, respectively (see Table 2 and Yu et al. (2008) for a full documentation of ingested data). After 1987, changes are evident in the lowest (most energetic) modes around 1997 and 1998 (an El Niño event) as well as 2000 and 2001 (La Niña). These changes are likely caused by wind speeds and SST changes associated with ENSO. All changes that are evident after 1987 are thus attributable to natural variability. The period of 1987-2006 is sufficiently long to observe events on the time-scale of ENSO but provides sufficient homogeneity for the purposes of this research. 


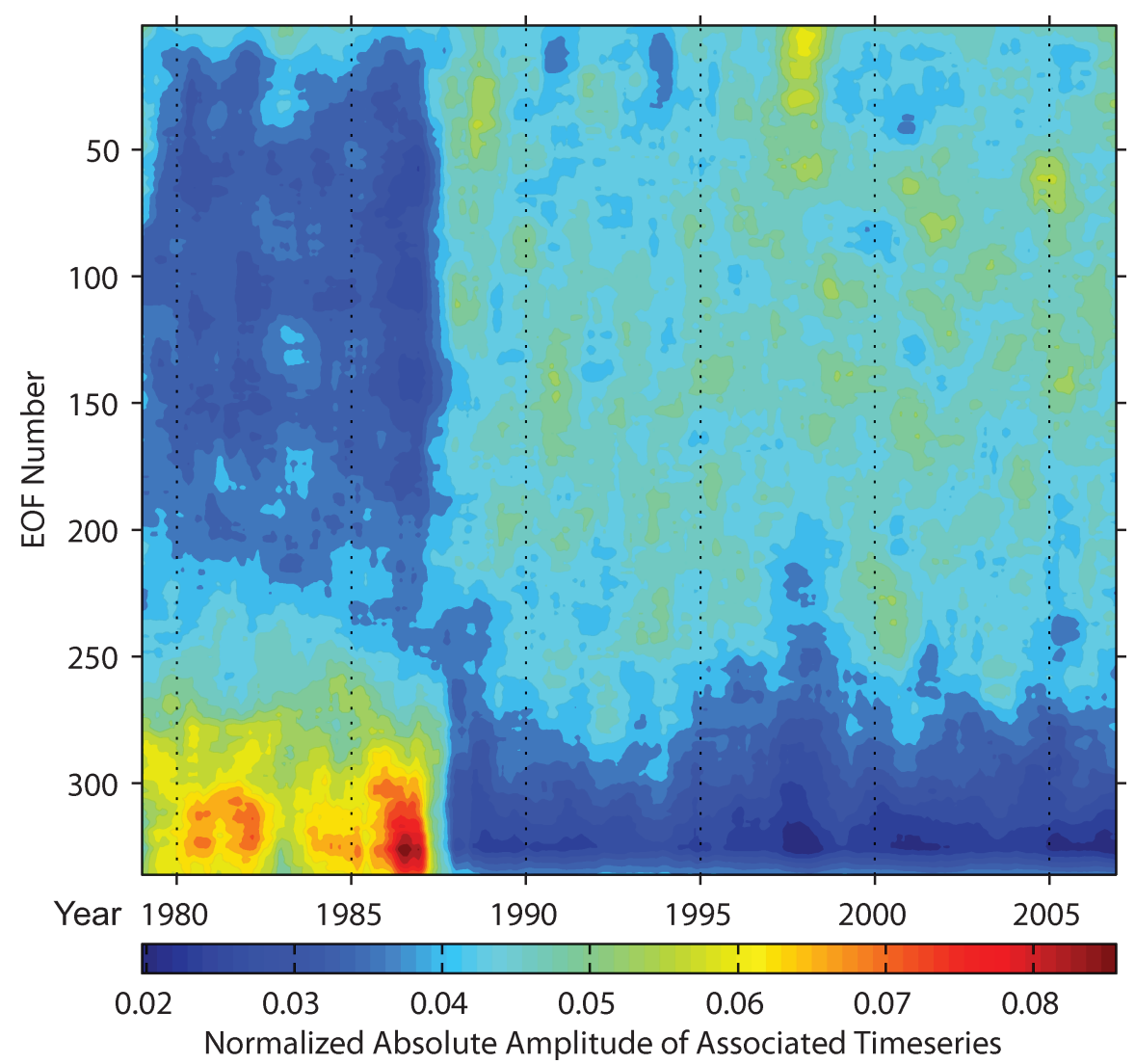

Figure 2. Filtered results of empirical orthogonal function (EOF) analysis of the GPCP precipitation dataset. The magnitude of all associated time series (color-coded) is plotted with respect to time and the number of the EOF. Changes in the EOF modes 50-340 clearly indicate a strong change in data composition around 1987, coinciding with the beginning of SSM/I data. Natural variability associated with El Niño is evident around 1997-1998.

Identical analyses have been performed for all other E datasets, and discontinuities corresponding to the change of input datasets as shown in Table 2 were identified in all datasets that provide fields before 1987, including re-analyses. A more thorough homogeneity analysis of re-analyses has been performed by Sterl (2004) for ERA-40 and Sturaro (2003) for NCEP-1/2. These find similar inhomogeneities and a near-homogeneous period starting with the introduction of SSM/I in July 1987.

To evaluate the homogeneity of $\mathrm{P}$ datasets, the same analysis technique as described for $\mathrm{E}$ datasets was used. This is shown for GPCP in Figure 2. The discontinuity caused by the introduction of SSM/I data in 1987 thus revealed is well documented (e.g. Adler et al., 2003; Yin et al., 2004) and precludes the use of the dataset as a continuous time-series before 1987 
without great caution. As in the case of $\mathrm{E}$, re-analyses are not free of discontinuities either, since the input data constrain the model change over time. Using the same homogeneity analysis, discontinuities similar to those of GPCP were identified in NCEP-1, NCEP-2 and ERA-40 P data (results not shown). The homogeneity analysis of CORE.2 P (not shown) exhibits a sharp discontinuity at 1979 (the beginning of the Outgoing Longwave Radiation (OLR) Precipitation Index (OPI) mission, see Table 2) and nearly identical results to GPCP for the remaining period with an additional inhomogeneity in 2002. All transition events correspond to the change of data sources, particularly the inclusion of satellite observations.

\section{Evaporation-precipitation over the ocean}

Based on the identified near-homogeneous period of 1987-2006, global balances of E, P and $\mathrm{R}$ can be constructed for all datasets as given in Table 1. It becomes evident that none of the datasets close the oceanic freshwater balance to 0 , but some even exceed the error bounds provided by the product, such as ERA-40. The datasets agreeing most closely with independent in-situ observations, OAFlux E and GPCP P, exhibit an imbalance of $+0.46 \mathrm{~Sv}$.

The error estimation in E, P and R datasets is difficult. In GPCP and OAFlux, a number of data based on in-situ and remotely sensed measurements are combined in an objective analysis. Not all data ingested provide reliable error estimates in the first place, but it is also unclear to what extent the estimates are correlated with each other temporally and spatially. While it is possible to arrive at an error estimate for each point using statistical methods, more detailed information about de-correlation space- and time scales would be needed for a full error propagation to produce global errors of $\mathrm{E}, \mathrm{P}$ or $\mathrm{R}$. It is possible that systematic errors play an important role, which might bias low an error analysis not taking this into account. It is unlikely that either $\mathrm{E}$ or $\mathrm{P}$ follow a normal distribution, rendering conventional statistical methods more difficult, still. Due to these constraints, the 'best case scenario' of decreasing the error by a factor of $\sqrt{N}$, where $\mathrm{N}$ is the number of observations, is clearly not realistic. A 'worst-case scenario' might be to average the error provided for each data point, which would result in error estimates of approximately $30 \%$ for P (Adler et al., 2003) and $10 \%$ for $\mathrm{E}$ (Yu et al., 2008), due to the different error handling in each product.

It is unlikely that we know $\mathrm{E}$ and $\mathrm{P}$ to an accuracy greater than 5\% due to the systematic spatial and temporal undersampling. A value of approximately 5-10\% also emerges from comparisons with independent in-situ observations (e.g. Quartly et al., 2007; Yu et al., 2008). Based on these numbers, we assume an error of approximately $10 \%$ for both $P$ and E. The annual mean precipitation into the ocean averaged over 19 years (1987-2006) is thus estimated at $12.2 \pm 1.2 \mathrm{~Sv}$, the evaporative loss is estimated at $13.0 \pm 1.3 \mathrm{~Sv}$, and the total freshwater influx is estimated at $1.25 \pm 0.1 \mathrm{~Sv}$. The system is in near steady state, as is shown by the thermal-expansion corrected sea-level rise of $0.02 \pm 0.01 \mathrm{~Sv}$ as estimated by satellite altimetry (Domingues et al., 2008). The net imbalance is found to be $0.5 \pm 1.8 \mathrm{~Sv}$. This means that the OAFlux-GPCP-R budget closes within the provided error estimates. The time-evolution of the balance is illustrated in Figure 3. 


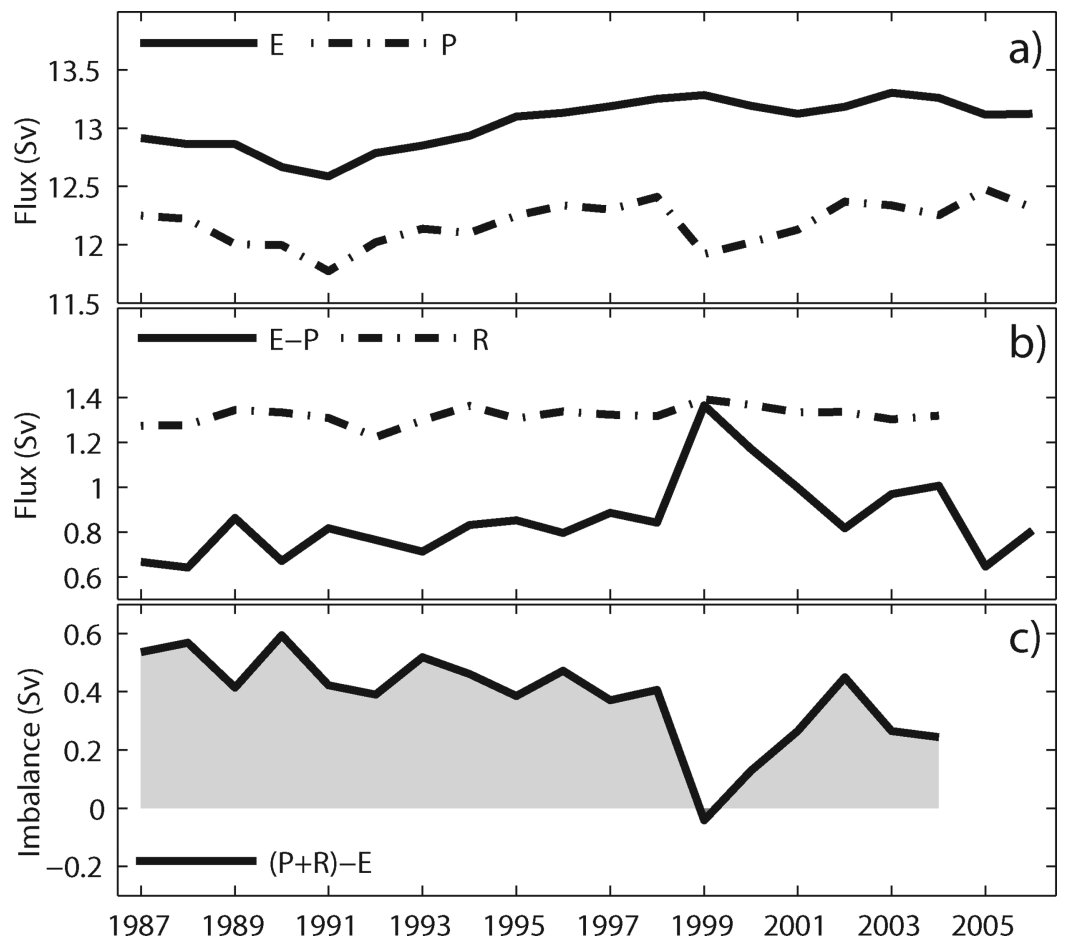

Figure 3. Global oceanic freshwater balance: (a) Mean annual OAFlux evaporation (E) from OAFlux (solid black line) and mean annual precipitation (P) from GPCP (dashed black line) from 19872006. (b) E-P for the same period (solid black line) from OAFlux and GPCP and global runoff ( $R$, dashed black line, see text) from 1987-2004. (c) Imbalance between (P+R)-E (solid black line). Positive regions (shaded in light gray) indicate a net influx to the ocean while negative regions (shaded in dark gray) indicate a net freshwater loss. All units are in $\mathrm{Sv}\left(10^{6} \mathrm{~m}^{3} \mathrm{~s}^{-1}\right)$. A mean imbalance of $+0.46 \mathrm{~Sv}$ (influx) is evident between data sources. The maximum imbalance of $+0.59 \mathrm{~Sv}$ is found in in 1990 while the only negative value $(-0.04 \mathrm{~Sv})$ occurs in 1999 .

\section{a. The Global picture}

The global mean E-P pattern based on OAFlux E and GPCP P between 1987-2006 is shown in Figure 4. It is evident that the subtropical gyres and western boundary currents of the Atlantic, Pacific and Indian oceans are all regions of net $\mathrm{E}$. The inter-tropical convergence zone (ITCZ) as well as high latitudes $\left(>40^{\circ}\right)$ are regions of net P. While both Atlantic subtropical gyres are net evaporative, the Pacific subtropical gyres - particularly the southern gyre - show an east-west transition with increased E near the eastern boundaries. Since E is a function of the relative humidity of the air overlying the water (Fairall et al., 2003), the air becomes saturated in humidity and $\mathrm{E}$ decreases as the overlying air is driven westward by the trade winds. From Figure 4 it is evident that the Atlantic is a net evaporative basin while the Pacific is neither strongly precipitative nor evaporative. In addition to the saturation of 


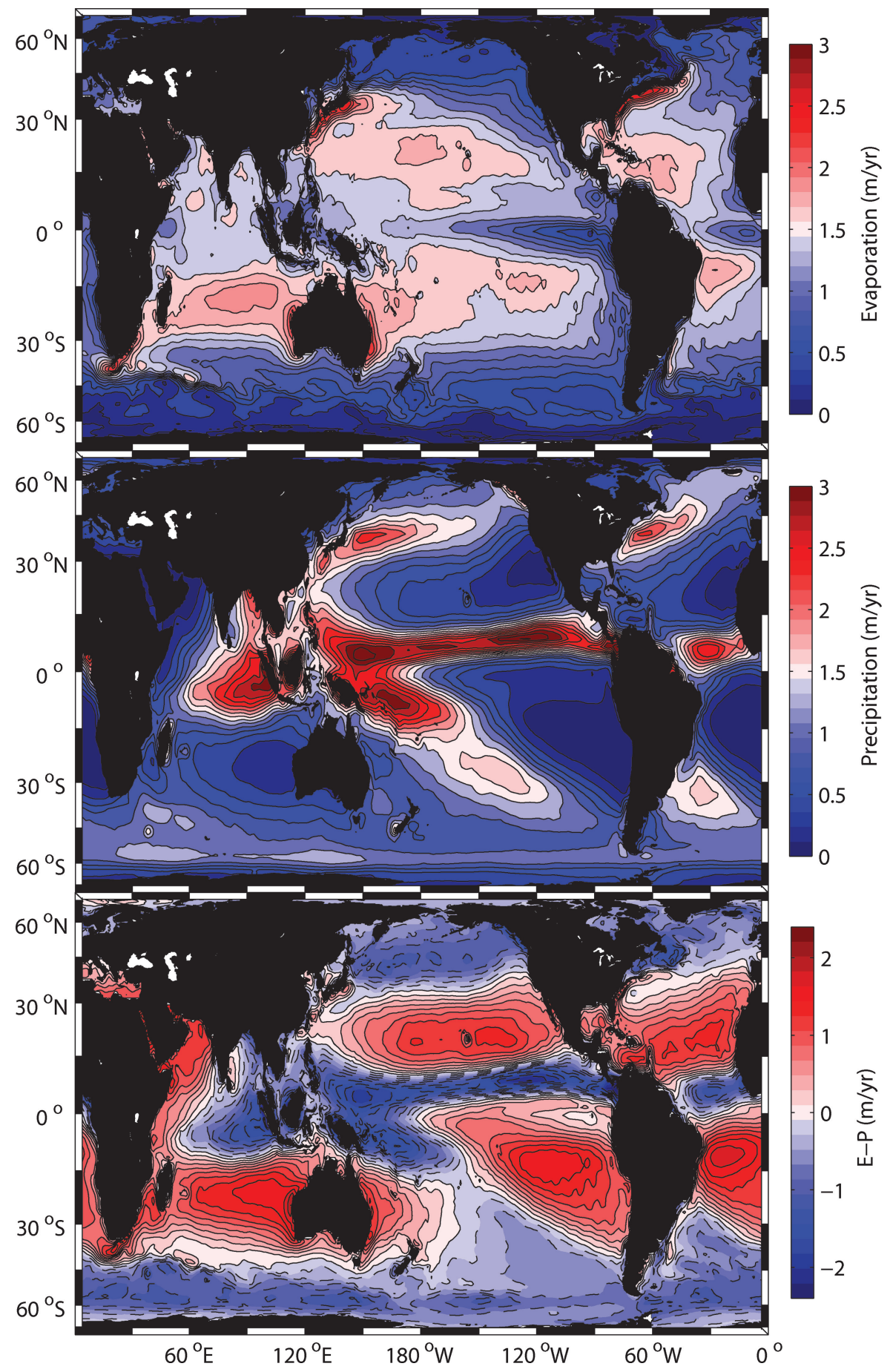

Figure 4. Global annual average E (top), P (middle) and E-P (bottom) maps for 1987-2006. All subtropical ocean gyres and subtropical marginal seas are dominated by excess $\mathrm{E}$, while the regions of the ITCZ and the Indonesian Throughflow as well as most temperate and subtropical latitudes are dominated by excess $\mathrm{P}$. The maximum imbalance (most water lost) of $2.22 \mathrm{~m} \mathrm{yr}^{-1}$ occurs in the Red Sea, while the minimum (most water gained) of $-2.59 \mathrm{~m} \mathrm{yr}^{-1}$ occurs near the Columbian Pacific coast in the ITCZ. 
air, this is likely caused by atmospheric moisture transport from the Atlantic to the Pacific over Central America (Weyl, 1968). This leads to the mean salinity of the Atlantic being greater than that of the Pacific (e.g. Durack and Wijffels, 2010, and references therein).

Strong seasonal patterns are present in the monthly data that were analyzed, which are not represented by the time-mean shown in Figure 4. To illustrate these temporal and spatial changes, a mean-removed area-corrected empirical orthogonal function (EOF) analysis, which was also used to analyze the homogeneity of the data, was re-run for the period of 1987-2006. The leading three modes (EOF1-3) are plotted in Figure 5. The associated time-series of the leading mode (EOF1) shows a near-sinusoidal annual pattern. This mode accounts for $29.4 \%$ of the total variability. The loading pattern (normalized to $-1 \ldots 1 \mathrm{~m} \mathrm{yr}^{-1}$ ) shows a significant annual meridional shift of the ITCZ by $5^{\circ}-10^{\circ}$ in both the Atlantic and the Pacific oceans. The eastern boundary currents are clearly evident, with the Gulf Stream and the Kuroshio Current having negative E-P values (net freshwater addition) in the Northern Hemisphere summer and positive values (net freshwater loss) in winter. This cycle correspondes to the monsoon regions in the Indian and Pacific oceans, which have the same sign as the eastern boundary currents in the Northern Hemisphere.

The associated time-series of the second leading mode (EOF2, explaining 9.2\% of the total variability) also shows a clear annual signal. However, a phase lag of approximately 2-3 months compared to the leading mode is present and a significant change in the El Niño winter of 1997-1998 is evident. All major eastern boundary currents are visible as positive signatures in the Northern Hemisphere and negative areas in the Southern Hemisphere. The sign is thus reversed from the leading mode. The annual meridional ITCZ shift is evident in this mode with the same sign as the leading mode.

The third leading mode (EOF3, explaining 5.3\% of the total variability) has a predominantly biannual associated time-series. The loading pattern is largely congruent with changes in $\mathrm{E}$ and $\mathrm{P}$ that would be expected to occur in an El Niño year, namely increased evaporation in the high sea-surface temperature area in the Central Pacific and enhanced precipitation in the area of the Western Pacific and the Indonesian Throughflow (Curtis, 2008). A strong peak in the associated time-series is evident in 1997-1998, corresponding to the strongest positive ENSO signal. The associated time series of EOF3 is strongly correlated to the Multivariate ENSO Index (MEI) and the loading pattern is similar to that of SST used in the creation of the MEI (Wolter and Timlin, 1993).

\section{b. Changes from previous estimates}

A significant increase in both spatial and temporal resolution has been achieved since estimates of oceanic E-P by Baumgartner and Reichel (1975) (hereafter BR75) and improved North Atlantic estimates by Schmitt et al. (1989) (hereafter SBD89). The positive signature of the Kuroshio Current was almost completely lacking in BR75 and is now clearly present. While the shape and magnitude of the South-Pacific subtropical gyre closely resemble 

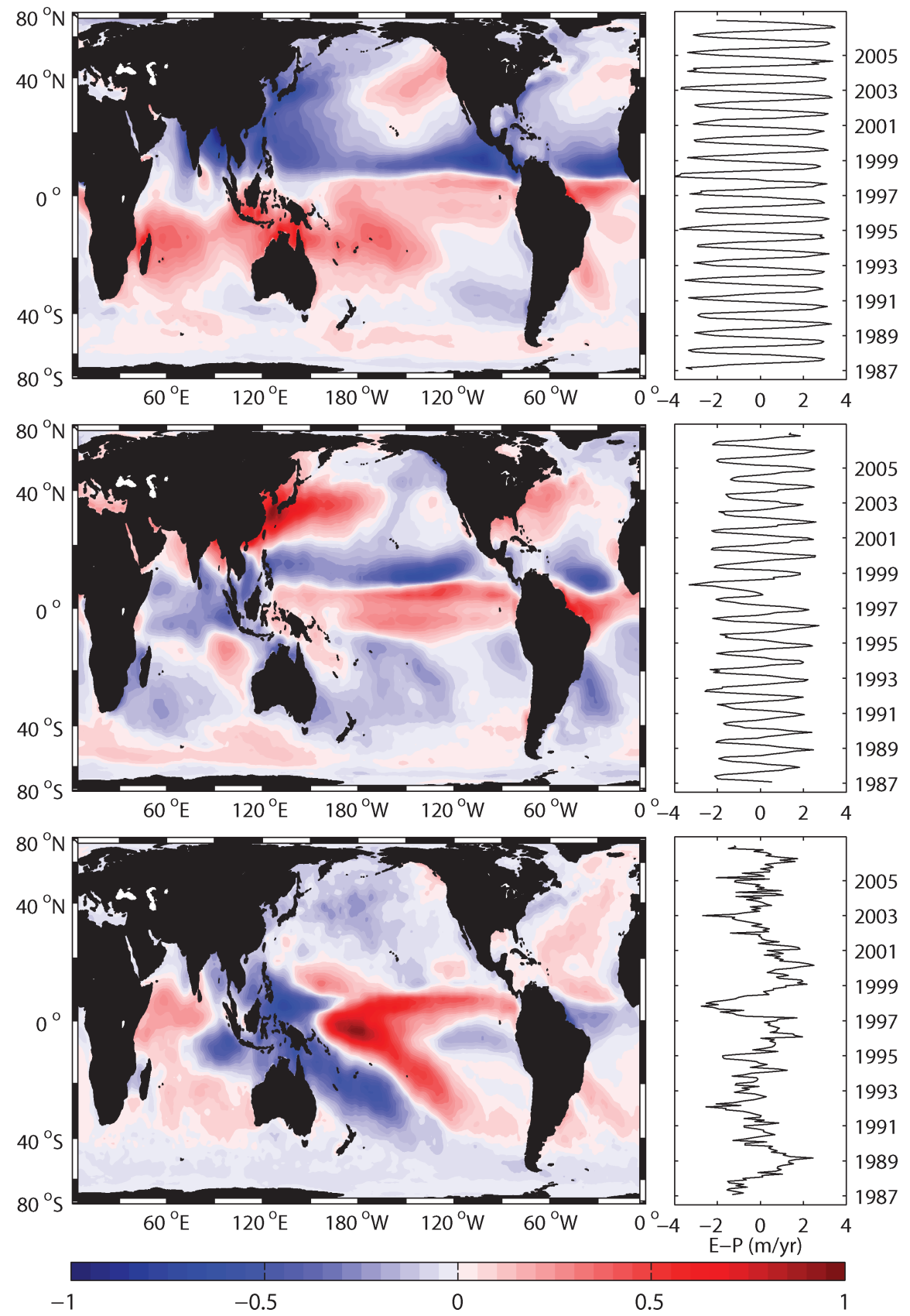

Figure 5. Results of area-corrected empirical orthogonal function (EOF) analysis. (a) Leading EOF Mode (EOF1) explaining $29.4 \%$ of total variability. (b) EOF2, explaining $9.2 \%$ of total variability. (c) EOF3, explaining 5.3\% of total variability. Both EOF1 and EOF2 exhibit a 12-month seasonal pattern in the associated time series with changes in 1997-1998 for EOF2. The seasonal ITCZ shift from its off-equator position to the near-equatorial position is evident in both modes. EOF3 shows changes in the spatial distribution of E-P in the Central and West Pacific. The associated time-series is dominated by the 1997-1998 El Niño event. 
those in BR75, the transition from net evaporative to net precipitative in the southern Indian Ocean occurs at lower latitudes than in BR75. Furthermore, BR75 showed most of the ocean adjacent to northeastern Australia to be negative (net precipitative), which is now identified as positive; particularly the area of the East Australian Current which was indicated as neutral in BR75 is shown as strongly evaporative in Figure 4. The negative sign in the Southern Ocean remains unchanged between BR75 and our estimate, but the magnitude is generally increased between $50-60^{\circ} \mathrm{S}$.

Compared to SBD89, the Atlantic is estimated to be more precipitative in subpolar latitudes, moving the line of neutral E-P to lower latitudes in general. While the Gulf Stream is present as a positive signal in our estimate, it is not as positive as in SBD89, and even becomes negative South of the Gulf Stream in an area that was previously estimated to have a net freshwater loss of approximately $0.8 \mathrm{~m} \mathrm{yr}^{-1}$. The magnitude of E-P in the subtropical gyre agrees well with estimates in SBD89, however. There is a closer agreement with modern satellite-based and re-analysis products, which we will discuss by integrating the total E-P-R fluxes.

\section{c. Derived freshwater transports between ocean basins}

From the estimates of E-P-R, it is possible to estimate freshwater transports between ocean basins by integrating E-P-R meridionally over each basin. This approach was used by Wijffels et al. (1992), hereafter W92, using data from BR75 and SBD89, by Dai and Trenberth (2003), hereafter DT03, using ECMWF data, by Talley (2008), hereafter T08, using the NCEP-1 re-analysis and by Large and Yeager (2009), hereafter LY09, using the CORE. 2 dataset.

This integration is performed with the presented global E-P-R dataset based on OAFlux and GPCP data from 1987-2006 (Fig. 6). As a constant of integration, the flux through Bering Strait is based on an estimate by Woodgate and Aagaard (2005), who find that the total (saltwater) flux is $0.8 \mathrm{~Sv}\left(1 \mathrm{~Sv}=10^{6} \mathrm{~m}^{3} \mathrm{~s}^{-1}\right)$ from the Pacific into the Arctic Ocean. We assume that the density of the water transported is $\approx 1025 \mathrm{~kg} \mathrm{~m}^{-3}$, which is equivalent to a mass transport of $0.82 \times 10^{9} \mathrm{~kg} \mathrm{~s}^{-1}$, which can be separated into salt transport $(\approx 3.5 \%$ of the total) and freshwater transport (96.5\%). We thus estimate a net water transport of $0.79 \mathrm{~Sv}$. It should be noted that there are significant uncertainties in these estimates and that there is a large seasonal and inter-annual variability in the transport through Bering Strait (Woodgate and Aagaard, 2005).

While the Bering Strait represents the only connection between the Pacific and the Arctic Ocean, there are multiple connections between the Arctic and the Atlantic Ocean. As a consequence there is no standard definition of boundaries. The following boundaries are used for this estimate: Robeson Channel (between the Northern Territories of Canada and Greenland), Parry Channel, Denmark Strait and the shortest possible straight line between Iceland and Norway. For simplicity, the boundary of the Southern Ocean is taken as $55^{\circ}$, close to Cape Horn. The boundary to the Indian Ocean is defined at $25^{\circ} \mathrm{W}$, and the transition 


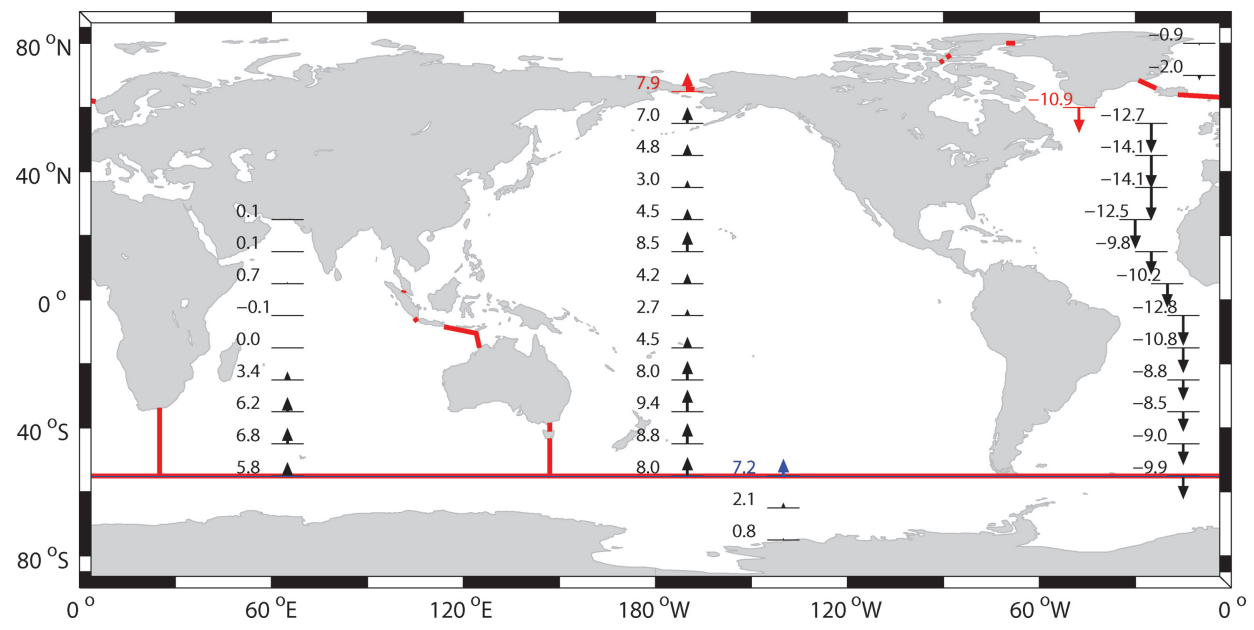

Figure 6. North-South integrated basin freshwater balance in $10^{5} \mathrm{~m}^{3} \mathrm{~s}^{-1}(0.1 \mathrm{~Sv})$, showing mean E-P-R integrals between 1987 and 2004. Added integration constants are indicated in red. All northward fluxes are positive, while southward fluxes are negative. A freshwater flow of $0.79 \mathrm{~Sv}$ through the Bering Strait is used to constrain the system. The resulting Arctic flux of $1.02 \mathrm{~Sv}$ is added to the northern boundary of the Atlantic (with no specified pathway). Iceberg forcings of $0.01 \mathrm{~Sv}$ and $0.06 \mathrm{~Sv}$ for Greenland and Antarctica, respectively, are added at the poles. The Southern Ocean is integrated from South to North and produces a net northward freshwater transport of $0.72 \mathrm{~Sv}$ into the Atlantic, Pacific and Indian basins at $55^{\circ}$. This is in contrast with the North-South integration of the other basins, which requires a northward flux of $0.39 \mathrm{~Sv}$ for the system to close. The total error of $0.33 \mathrm{~Sv}$ cannot be constrained to a specific basin.

between the Indian Ocean and the Pacific is defined along Tasmania and the Indonesian Throughflow. These definitions are indicated geographically in Figure 6.

The Arctic Ocean is a net precipitative region and the combined E-P and riverine influx increase the value of $0.79 \mathrm{~Sv}$ through the Bering Strait by $0.3 \mathrm{~Sv}$ to $1.09 \mathrm{~Sv}$ when it reaches the Atlantic Ocean. As previously stated, the Atlantic is a net evaporative basin, and $0.1 \mathrm{~Sv}$ is lost. This includes the strongly net evaporative Mediterranean Sea. It should be noted that when the Atlantic Ocean is further separated from its high-latitude marginal seas (such as the Labrador Sea and the Hudson Bay), the basin becomes more evaporative, which is indicated by the maximum southward transport of $1.41 \mathrm{~Sv}$ at $45^{\circ} \mathrm{N}$. The Southern Ocean, akin to the Arctic Ocean, is an area dominated by $\mathrm{P}$ and as a consequence adds $0.72 \mathrm{~Sv}$ of freshwater to the other oceans (indicated by a blue arrow). The Indian Ocean is strongly evaporative, leading to a net loss of $0.58 \mathrm{~Sv}$ of water. It is clear that the numbers at $55^{\circ} \mathrm{S}$ cannot add up to 0 , since the balance of E-P-R is not fully closed, but has an imbalance of $0.32 \mathrm{~Sv}$. This number differs slightly from the estimates in Table 1 due to the integration period being shorter and the application of a slightly different land mask.

The boundaries chosen for this integration are somewhat different from previous estimates (W92, DT03) in that the boundaries between the Indian, the Pacific (both $35^{\circ} \mathrm{S}$ ) and the 
Atlantic $\left(45^{\circ} \mathrm{S}\right)$ to the Southern Ocean are moved to $55^{\circ} \mathrm{S}$. The estimates by T08 and LY09 use different boundary definitions altogether.

Nonetheless, significant changes from other estimates are evident. Compared to W92, who found a strongly evaporative Atlantic and a strongly precipitative Pacific, we find the Atlantic to be less net evaporative and the Pacific to be neither evaporative nor precipitative. Consequently, the difference between the Atlantic and Pacific is not as pronounced. While our estimates of the strong evaporative role of the Indian Ocean are comparable to those found by W92, DT03 found the excess E to be less than either our estimate or the W92 estimate. Compared to W92, the Southern Ocean is much more precipitative in both our and the DT03 estimates.

The most recent publications (T08 and LY09) used in this comparison agree well with our estimates of the Pacific and indicate only a marginally net precipitative state. However, the Southern Ocean in T08 is significantly less precipitative than in our estimate, but is similar to LY09. We find the Indian Ocean is significantly more evaporative in our estimate than in T08 and slightly more evaporative than in LY09.

\section{Discussion and conclusions}

A new estimate of E-P-R based on state-of-the-art long-term $\mathrm{E}$ and $\mathrm{P}$ products as well as the most complete dataset for $\mathrm{R}$ has been assembled based on the OAFlux evaporation fields, the GPCP precipitation product and a combination of the Dai and Trenberth (2002) and Dai et al. (2009) riverine runoff for the seasonal cycle and the inter-annual variability, respectively. These datasets were chosen out of a total of seven $\mathrm{E}$ datasets and seven $\mathrm{P}$ datasets, primarily based on a review of inter-comparisons with independent data but also based on homogeneity analyses and oceanic freshwater budget closure calculations.

Inhomogeneities were identified in all seven E and seven P datasets before 1987, attributable to the inclusion of SSM/I satellite data thereafter. A number of datasets are available long before this period, and we caution any user of such datasets to be wary of inhomogeneities caused by advent of satellites and avoid using data predating 1987 if possible. Based on these analyses, the period of 1987-2006 was identified as suitable for constructing a global climatology of E-P-R using OAFlux and GPCP. The selected datasets have been shown in inter-comparisons to outperform re-analysis estimates consistently. While OAFlux and GPCP are deemed to be amongst the state-of-the-art, it should be noted that they might not be ideally suited for every application. This estimate of E-P-R shows a significant improvement in both spatial and temporal detail from older, in-situ-only estimates by Baumgartner and Reichel (1975) and Schmitt et al. (1989), particularly in regions of boundary currents. The differences from modern estimates are less obvious, but still significant.

With the available time-period, the analysis of seasonal variations as well as limited insights into inter-annual variability of the global freshwater cycle become possible. This is shown by a clear presence of the El Niño Southern Oscillation, as revealed by an EOF 
analysis of the OAFlux/GPCP E-P estimate. The third leading EOF mode was found to be closely correlated to the Multivariate ENSO Index(MEI) and the associated loading pattern agreed well with the sea-surface temperature loading pattern that is used to produce the MEI.

Our findings support other studies (e.g. Dai and Trenberth, 2003; Talley, 2008) which found the Pacific to be less precipitative and the Atlantic to be less evaporative than previously thought (Wijffels et al., 1992). The Southern Ocean, however, is estimated to be more precipitative and the Indian Ocean more evaporative than in Wijffels et al. (1992).

The annual mean precipitation into the ocean averaged over 19 years (1987-2006) is estimated at $12.2 \pm 1.2 \mathrm{~Sv}$, the evaporative loss is estimated at $13.0 \pm 1.3 \mathrm{~Sv}$, and the total freshwater input from land is estimated at $1.25 \pm 0.1 \mathrm{~Sv}$. Since the global sea-level rise is only an insignificant departure from steady state, the net imbalance is found to be $0.5 \pm 1.8 \mathrm{~Sv}$. The system thus closes within the errors estimated for each data set. The remaining imbalance, equivalent to $4 \%$ of oceanic evaporation, could be caused by either $\mathrm{E}$ or $\mathrm{P}$ alone or any combination of $\mathrm{E}, \mathrm{P}$ and R. Evaporation might be biased low by a systematic undersampling of small-scale and extreme events such as narrow boundary currents or extreme winds. With improved satellite measurements and continued in-situ sampling, it should be possible to further constrain the source of such errors in the future.

Acknowledgments. The authors would like to acknowledge support from the National Science Foundation, grant \#OCE-0647949. Data preparation and conversion by Xiangze Jin are greatly appreciated. Helpful comments by anonymous reviewers and Kevin Trenberth are gratefully acknowledged.

\section{REFERENCES}

Adler, R., G. Huffman, A. Chang, R. Ferraro, P. Xie, J. Janowiak, B. Rudolf, U. Schneider, S. Curtis, D. Bolvin, et al. 2003. The Version-2 Global Precipitation Climatology Project (GPCP) Monthly Precipitation Analysis (1979-Present). J. Hydrometeorol., 4, 1147-1167.

Baumgartner, A. and E. Reichel. 1975. World Water Balance: Mean Annual Global, Continental and Maritime Precipitation, Evaporation and Runoff, Elsevier Scientific, Amsterdam, 182 pp.

Bosilovich, M., S. Schubert, G. Kim, R. Gelaro, M. Rienecker, M. Suarez, J. Bacmeister, R. Todling, and J. Chen. 2006. NASA's Modern Era Retrospective-analysis for Research and Applications (MERRA), in AGU Fall Meeting Abstracts, Vol. 1, page 3.

Box, J., D. Bromwich, B. Veenhuis, L. Bai, J. Stroeve, J. Rogers, K. Steffen, T. Haran, and S. Wang. 2006. Greenland ice sheet surface mass balance variability (1988-2004) from calibratedPolar MM5 output. J. Climate, 19, 2783-2800.

Brutsaert, W. 1982. Evaporation into the Atmosphere, Kluwer Academic Publishers, 316 pp.

Chou, S., R. Atlas, C. Shie, and J. Ardizzone. 1995. Estimates of surface humidity and latent heat fluxes over oceans from SSM/I data. Mon. Wea. Rev., 123, 2405-2425.

Chou, S., E. Nelkin, J. Ardizzone, R. Atlas, and C. Shie. 2003. Surface turbulent heat and momentum fluxes over global oceans based on the Goddard satellite retrievals, Version 2 (GSSTF2). J. Climate, $16,3256-3273$.

Curtis, S. 2008. The El Niño-Southern Oscillation and global precipitation. Geography Compass, $2 / 3,600-619$. 
Dai, A. and K. Trenberth. 2002. Estimates of freshwater discharge from continents: Latitudinal and seasonal variations. J. Hydrometeorol., 3, 660-687.

- 2003. New estimates of continental discharge and oceanic freshwater transport, in AMS Symp. on Observing and Understanding the Variability of Water in Weather and Climate, 9-13 February, 2003, Long Beach, CA.

Dai, A., T. Qian, K. E. Trenberth, and J. D. Milliman. 2009. Changes in continental freshwater discharge from 1948 to 2004. J. Climate, 22, 2773-2792.

Divakarla, M., C. Barnet, M. Goldberg, L. McMillin, E. Maddy, W. Wolf, L. Zhou, and X. Liu. 2006. Validation of atmospheric infrared sounder temperature and water vapor retrievals with matched radiosonde measurements and forecasts. J. Geophys. Res-Atmos., 111, D09S15.

Domingues, C., J. Church, N. White, P. Gleckler, S. Wijffels, P. Barker, and J. Dunn. 2008. Improved estimates of upper-ocean warming and multi-decadal sea-level rise. Nature, 453, 1090-1093.

Durack, P. and S. Wijffels. 2010. Fifty-year trends in global ocean salinities and their relationship to broad-scale warming. J. Climate, 23, 4342-4362.

Fairall, C., E. Bradley, J. Hare, A. Grachev, and J. Edson. 2003. Bulk parameterization of air-sea fluxes: Updates and verification for the COARE algorithm. J. Climate, 16, 571-591.

Fairall, C., E. Bradley, D. Rogers, J. Edson, and G. Young. 1996. The TOGA COARE bulk flux algorithm. J. Geophys. Res., 101, 3747-3764.

Fekete, B., C. Vörösmarty, J. Roads, and C. Willmott. 2004. Uncertainties in precipitation and their impacts on runoff estimates. J. Climate, 17, 294-304.

Goodberlet, M., C. Swift, and J. Wilkerson. 1990. Ocean surface wind speed measurements of the special sensorMicrowave/Imager (SSM/I). IEEE Trans. Geosci. Remote Sens., 28, 823-828.

Hartmann, D. 1994. Global Physical Climatology, 56, International Geophysics, Academic Press, 411 pp.

Josey, S. 2001. A Comparison of ECMWF, NCEP-NCAR, and SOC surface heat fluxes with moored buoy measurements in the subduction region of the northeast Atlantic. J. Climate, 14, 1780-1789.

Josey, S., E. Kent, and P. Taylor. 1998. The Southampton Oceanography Centre (SOC) oceanatmosphere heat, momentum and freshwater flux atlas. Technical report, National Oceanography Centre, Southampton, UK.

Kanamitsu, M., W. Ebisuzaki, J. Woollen, S. Yang, J. Hnilo, M. Fiorino, and G. Potter. 2002. NCEPDOE AMIP-II Reanalysis (r-2). Bull. Amer. Meteor. Soc., 83, 1631-1643.

Kistler, R., E. Kalnay, W. Collins, S. Saha, G. White, J. Woollen, M. Chelliah, W. Ebisuzaki, M. Kanamitsu, V. Kousky, et al. 2001. The NCEP-NCAR 50-Year Reanalysis: Monthly means CDROM and documentation. Bull. Amer. Meteor. Soc., 82, 247-267.

Large, W. and S. Yeager. 2009. The global climatology of an interannually varying air-sea flux data set. Climate Dyn., 33, 341-364.

Monaghan, A., D. Bromwich, and S. Wang. 2006. Recent trends in Antarctic snow accumulation from Polar MM5 simulations. Philos. T. Roy. Soc. A, 364, 1683.

NCAR. 2010. U.S. National Center for Atmospheric Research [Climate and Global Dynamics Division], U.S. Geophysical Fluid Dynamics Laboratory [NOMADS], U.K. Hadley Centre for Climate Prediction and Research, and U.S. National Centers for Environmental Prediction, updated half-yearly: CORE.2 Global Air-Sea Flux Dataset Dataset ds260.2 published by the CISL Data Support Section at the National Center for Atmospheric Research, Boulder, CO, available online at http://dss.ucar.edu/datasets/ds260.2/.

New, M., M. Todd, M. Hulme, and P. Jones. 2001. Precipitation measurements and trends in the twentieth century. Int. J. Climatol., 21, 1899-1922. 
Quartly, G., E. Kyte, M. Srokosz, and M. Tsimplis. 2007. An intercomparison of global oceanic precipitation climatologies. J. Geophys. Res-Atmos., 112, D10121.

Robinson, I. 2004. Measuring the Oceans from Space: The Principles and Methods of Satellite Oceanography, Springer, $669 \mathrm{pp}$.

Roderick, M. and G. Farquhar. 2002. The cause of decreased pan evaporation over the past 50 years. Science, 298, 1410-1411.

Sapiano, M. and P. Arkin. 2009. An intercomparison and validation of high-resolution satellite precipitation estimates with 3-hourly gauge data. J. Hydrometeorol., 10, 149-166.

Schmitt, R., P. Bogden, and C. Dorman. 1989. Evaporation minus precipitation and density fluxes for the North Atlantic. J. Phys. Oceanogr., 19, 1208-1221.

Schulz, J., P. Schluessel, and H. Grassl. 1993. Water vapour in the atmospheric boundary layer over oceans from SSM/I measurements. Int. J. Remote Sens., 14, 2773-2789.

Shepherd, A. and D. Wingham. 2007. Recent sea-level contributions of the Antarctic and Greenland ice sheets. Science, $315,1529$.

Simmons, A., S. Uppala, D. Dee, and S. Kobayashi. 2007. ERA-Interim: New ECMWF reanalysis products from 1989 onwards. ECMWF Newsletter, 110, 25-35.

Smith, E., J. Vazquez, A. Tran, and R. Sumagaysay. 1996. Satellite-derived sea surface temperature data available from the NOAA/NASA Pathfinder Program. Eos, Transactions, American Geophysical Union, 77, 135.

Spencer, R., H. Goodman, and R. Hood. 1989. Precipitation retrieval over land and ocean with the SSM/I: Identification and characteristics of the scattering signal. J. Atmos. Oceanic Technol., 6, 254-273.

Sterl, A. 2004. On the (in) homogeneity of reanalysis products. J. Climate, 17, 3866-3873.

Sturaro, G. 2003. A closer look at the climatological discontinuities present in the NCEP/NCAR reanalysis temperature due to the introduction of satellite data. Climate Dyn., 21, 309-316.

Talley, L. 2008. Freshwater transport estimates and the global overturning circulation: Shallow, deep and throughflow components. Prog. Oceanogr., 78, 257-303.

Trenberth, K., L. Smith, T. Qian, A. Dai, and J. Fasullo. 2007. Estimates of the global water budget and its annual cycle using observational and model data. J. Hydrometeorol., 8, 758-769.

Uppala, S., P. Kållberg, A. Simmons, U. Andrae, V. Da Costa Bechtold, M. Fiorino, J. Gibson, J. Haseler, A. Hernandez, G. Kelly, et al. 2005. The ERA-40 re-analysis. Quart. J. Roy. Meteor. Soc., 131, 2961-3012.

Vaughan, D., J. Bamber, M. Giovinetto, J. Russell, and A. Cooper. 1999. Reassessment of net surface mass balance in Antarctica. J. Climate, 12, 933-946.

Weyl, P. 1968. The role of the oceans in climatic change: A theory of the ice ages. Meteor. Mon., 8 , 37-62.

Wijffels, S., R. Schmitt, H. Bryden, and A. Stigebrandt. 1992. Transport of freshwater by the oceans. J. Phys. Oceanogr., 22, 155-162.

Wolter, K. and M. Timlin. 1993. Monitoring ENSO in COADS with a seasonally adjusted principal component Index, in Proc. 17th Climate Diagnostics Workshop, 52-57.

Woodgate, R. and K. Aagaard. 2005. Revising the Bering Strait freshwater flux into the Arctic Ocean. Geophys. Res. Lett., 32, L02602.

Woodruff, S., R. Slutz, R. Jenne, and P. Steurer. 1987. A comprehensive ocean-atmosphere data set. Bull. Amer. Meteor. Soc., 68, 1239-1250.

Wunsch, C. and P. Heimbach. 2007. Practical global oceanic state estimation. Physica D, 230, 197208.

Xie, P. and P. Arkin. 1997. Global precipitation: A 17-year monthly analysis based on gauge observations, satellite estimates, and numerical model outputs. Bull. Amer. Meteor. Soc., 78, 2539-2558. 
Yin, X., A. Gruber, and P. Arkin. 2004. Comparison of the GPCP and CMAP Merged Gauge: Satellite Monthly Precipitation Products for the Period 1979-2001. J. Hydrometeorol., 5, 1207-1222.

Yu, L., X. Jin, and R. A. Weller. 2008. Multidecade Global Flux Datasets from the Objectively Analyzed Air-sea Fluxes (OAFlux) Project: Latent and Sensible Heat Fluxes, Ocean Evaporation, and Related Surface Meteorological Variables. Technical Report OAFlux Project Technical Report (OA2008-01), Woods Hole Oceanographic Institution.

Yu, L. and R. Weller. 2007. Objectively analyzed air-sea heat fluxes for the global ice-free oceans (1981-2005). Bull. Amer. Meteor. Soc., 88, 527-539.

Zeng, L., P. Shi, W. Liu, and D. Wang. 2009. Evaluation of a satellite-derived latent heat flux product in the South China Sea: A comparison with moored buoy data and various products. Atmos. Res., 94, 91-105.

Received: 29 January, 2010; revised: 26 October, 2010. 